\title{
Erratum
}

\section{The new plant virus family Flexiviridae and assessment of molecular criteria for species demarcation}

\author{
M. J. Adams et al. [Arch. Virol (2004) 149: 1045-1060] \\ DOI 10.1007/s00705-004-0304-0
}

Owing to a misunderstanding, the name of S. K. Zavriev, Laboratory of Molecular Virology, Institute of Agricultural Biotechnology, Moscow, Russia (chair of the Allexivirus study group) was omitted from the list of authors. The first author, M. J. Adams, apologises for this omission.

Authors should be cited as:

M. J. Adams, J. F. Antoniw, M. Bar-Joseph, A. A. Brunt, T. Candresse, G. D. Foster, G. P. Martelli, R. G. Milne, S. K. Zavriev, and C. M. Fauquet

\footnotetext{
Verleger: Springer-Verlag GmbH, Sachsenplatz 4-6, 1201 Wien, Austria. - Herausgeber: Dr. M. H. V. Van Regenmortel, École Supérieure de Biotechnologie de Strasbourg (ESBS), Parc d'Innovation, Boulevard Sébastian Brandt, 67400 Illkirch, France. - Redaktion: Sachsenplatz 4-6, 1201 Wien, Austria. - Satz und Umbruch: Thomson Press (India) Ltd., Chennai, India. - Offsetdruck: Holzhausen Druck \& Medien GmbH, Holzhausenplatz 1, 1140 Wien, Austria. Herstellungsort: Wien, Austria. - Printed in Austria.
} 